\title{
Assessment of wind impact on building air leakage measurements using a model scale experiment
}

\author{
Adeline Bailly Mélois ${ }^{1,2 *}$, Anh Dung Tran ${ }^{1,2}$, Mohamed El Mankibi ${ }^{2}$, François Rémi Carrié ${ }^{3}$, Bassam Moujalled ${ }^{1}$ and Gaëlle \\ Guyot $^{1}$
}

${ }^{1}$ CEREMA BPE Project Team, 46 rue Saint Théobald - BP128, 38081 L'Isle d'Abeau Cedex, France

${ }^{2}$ ENTPE LTDS, 3 rue Maurice Audin, 69518 Vaulx-en-Velin, France

${ }^{3}$ ICEE, 93 rue Molière, 69003 Lyon, France

\begin{abstract}
Nowadays, many countries include requirements for building airtightness in their current national regulations or energy-efficiency programs, mainly for concern about reducing building energy consumption due to air leakage. Moreover, more and more countries impose a mandatory justification with an air leakage measurement at building commissioning. Therefore, the uncertainty of the measurements results has become a key concern in several countries over the past year. More specifically, the influence of wind speed has been identified as one of the major sources of error on the measurement result. The goal of this paper is to present the experimental facility we design and built to improve the uncertainty estimates and the measurement protocol based on model scale experiments in controlled laboratory conditions. We first present the similarity criteria we identified for our model scale experiment. Secondly, we present the experimental design. Finally, we characterize the wind speed inside the wind tunnel and we present the preliminary results regarding the reproduction of fan pressurization tests on the model for different leakage distributions.
\end{abstract}

\section{Nomenclature}

\begin{tabular}{|l|l|}
\hline$A$ & Area of opening $\left(\mathrm{m}^{2}\right)$ \\
\hline$c_{p}$ & $\begin{array}{l}\text { Specific heat capacity at constant pressure (= } \\
\left.1,004 \mathrm{~J} \mathrm{~kg}^{-1} \mathrm{~K}^{-1}\right)\end{array}$ \\
\hline$c_{v}$ & $\begin{array}{l}\text { Specific heat capacity at constant volume } \\
\left(=1.4 c_{p}\right)\left(\mathrm{J} \mathrm{kg}^{-1} \mathrm{~K}^{-1}\right)\end{array}$ \\
\hline$C_{p w}$ & Wind pressure coefficients (-) \\
\hline$C_{z}$ & Discharge coefficients (-) \\
\hline$E L A_{4}$ & $\begin{array}{l}\text { Equivalent leakage area at } 4 \mathrm{~Pa} \text { (according to } \\
\text { ISO 9972) }\left(\mathrm{m}^{2}\right)\end{array}$ \\
\hline$L$ & Length (m) \\
\hline$r_{L D}$ & Leakage distribution ratio (-) \\
\hline$m$ & Mass (kg) \\
\hline$p_{i}$ & $\begin{array}{l}\text { Pressure relative to external atmospheric } \\
\text { pressure (Pa) }\end{array}$ \\
\hline$q$ & Volumetric airflow rate $\left(\mathrm{m}^{3} \mathrm{~s}^{-1}\right)$ \\
\hline$q_{m}$ & Mass airflow rate (kg s $\left.{ }^{-1}\right)$ \\
\hline$t$ & Time (s) \\
\hline$T$ & Temperature (K) \\
\hline$U$ & Wind speed at the building level (m s $\left.{ }^{-1}\right)$ \\
\hline$V$ & Internal building volume (m $\left.{ }^{3}\right)$ \\
\hline$z$ & Altitude above ground level (m) \\
\hline$\rho$ & Air density (kg m $\left.{ }^{-3}\right)$ \\
\hline$\Delta p$ & $\begin{array}{l}\text { Pressure difference between the outside and } \\
\text { the inside of the building (Pa) }\end{array}$ \\
\hline$O$ & $\begin{array}{l}\text { Referring to standard conditions }(293.15 \mathrm{~K}, \\
101,32510^{5} \text { Pa) }\end{array}$ \\
\hline$i$ & Pertaining to inside the building \\
\hline
\end{tabular}

\begin{tabular}{|l|l|}
\hline$p d$ & $\begin{array}{l}\text { Pertaining to pressurisation measurement } \\
\text { device }\end{array}$ \\
\hline 1,2 & Pertaining to opening number 1 or 2 \\
\hline
\end{tabular}

\section{Introduction}

Since the 1970s, many authors have discussed the impact of poor airtightness on building energy use, indoor air quality, building damage, or noise transmission [1-7]. Nowadays, because poor airtightness affects significantly the energy performance of buildings, and even more significantly with low-energy targets, many countries include requirements for building airtightness in their national regulations or energy-efficiency programs [8]. Building pressurization tests are increasingly used for compliance checks to energy performance requirements and may result in severe penalties [9]. Therefore, the uncertainty of the measurement results has become a key concern in several countries over the past few years. More specifically, several studies [10-14] have shown the significant uncertainties induced by the wind. Nevertheless, we need further investigations to understand how the wind affects pressurization tests and to characterize the error induced by the wind on the test results. One solution is to perform pressurization tests using model scale experiments. Indeed, this method led to perform tests on a model for which we know the exact envelope airtightness. Thus, we are able to evaluate the exact error induced by the wind on a measurement result. Another advantage of model scale experiment is the

\footnotetext{
${ }^{*}$ Corresponding author: adeline.melois@,cerema.fr
} 
possibility to study various configurations of wind speed and airleakage distribution in laboratory conditions. The objective of this study is to reproduce fan pressurization tests at model scale in a wind tunnel in order to study the impact of the wind on the results.

\section{Methodology for experiment sizing}

In order to reproduce fan pressurization tests at model scale, we need to define sizes and characteristics for:

- The model that will reproduce a single-zone building;

- The measuring device that will replace a blowerdoor;

- The wind tunnel that will reproduce the wind.

\subsection{Simplified description of a pressurization test on a single-zone building}

We design a model able to conduct controlled experiments in laboratory conditions. Similarly to Carrié and Leprince $[11,12]$, we assume that the building can be represented by a single zone model that consists in only two types of wall regarding pressure behaviour: the windward walls and the leeward walls. Thus, we assume that all leakages can be represented by only two leakages: a first one on the windward side and a second one on the leeward side. One specific challenge in model scale experiments is to achieve similarity conditions. To this end, we analyse the fundamental equations governing the pressurisation tests we defined in a previous work [15].

In order to study only the wind impact, we consider initial isothermal conditions. As we will perform the tests in laboratory conditions, we expect that the temperatures, and thus the air densities, will not significantly vary during each test. Thus, we can neglect the impact of the density differences in the pressure differences definition given in equations (1) and (2).

Equations (3) and (4) give the airflow through respectively the windward side opening and the leeward side opening. The mass balance applied in our model gives equation (5) and the energy conservation gives equation (6).

$$
\begin{gathered}
\Delta p_{1}(t)=C_{p w, 1} \frac{\rho_{0} U(t)^{2}}{2}-p_{i}(t) \\
\Delta p_{2}(t)=C_{p w, 2} \frac{\rho_{0} U(t)^{2}}{2}-p_{i}(t) \\
\frac{4 C_{z, 1} A_{1}^{3}{ }^{3 / 2}}{\sqrt{\pi}} \frac{d q_{1}(t)}{d t}=-q_{1}^{2}(t) \operatorname{sign}\left(q_{1}(t)\right)+2 C_{z, 1}^{2} A_{1}^{2} \frac{\Delta p_{1}(t)}{\rho_{0}} \\
\frac{4 C_{z, 2} A_{2}{ }^{3 / 2}}{\sqrt{\pi}} \frac{d q_{2}(t)}{d t}=-q_{2}^{2}(t) \operatorname{sign}\left(q_{2}(t)\right)+2 C_{z, 2}^{2} A_{2}^{2} \frac{\Delta p_{2}(t)}{\rho_{0}} \\
\frac{d m_{i}(t)}{d t}=V_{i} \frac{d \rho_{i}(t)}{d t}=q_{m, p d}(t)+q_{m, 1}(t)+q_{m, 2}(t) \\
V_{i} c_{v} \frac{d\left(\rho_{i}(t) T_{i}(t)\right)}{d t}=\rho_{p d} c_{p} q_{p d} T_{p d}+\rho_{1} c_{p} q_{1} T_{1}+\rho_{2} c_{p} q_{2} T_{2}
\end{gathered}
$$

\subsection{Equation in non-dimensional form}

To define similarity conditions between real scale tests and model scale experiment, we need to perform a dimensional analysis that will bring out non-dimensional numbers. The conservation of the values of these numbers between the scales will guarantee the similarity. In order to identify these numbers, we introduce a reference size $\mathrm{X}_{\text {ref }}$ and a non-dimensional variable $\mathrm{X}^{*}$ for each dimensional variable $X$ of these 6 equations, according to the method described by N. Le Roux [16]. Equation (7) gives the relation between $\mathrm{X}^{*}, \mathrm{X}$ and $\mathrm{X}_{\text {ref. }}$.

$$
X^{*}=\frac{X}{X_{\text {ref }}}
$$

As the purpose of our analysis is to define the sizes of our experiment in similarity conditions, we first study a specific configuration with two identical openings (same size and same height) in isothermal initial conditions. Equations (1) and (2) are similar, one for each opening. Thus, we introduce dimensionless variables in a generic equivalent equation. We obtain the first dimensionless number in equation (8). Equations (3) and (4) are also " similar " for both openings. Thus, we introduce dimensionless variables in one generic equivalent equation. We define $t_{r e f}=\frac{L_{r e f}}{U_{r e f}}$ with $L_{r e f}$ a characteristic length. We then obtain a second and a third dimensionless numbers in equation (9). Now we introduce the dimensionless variables in the mass balance and the energy conservation equations. We obtain the fourth dimensionless number both in equations (10) and (11).

$$
\begin{aligned}
& \Delta p^{*}=\left(\frac{\boldsymbol{\rho}_{\text {ref }} \boldsymbol{U}_{\text {ref }}{ }^{2}}{\boldsymbol{p}_{\text {ref }}}\right) C_{p w} \frac{\rho^{*} U^{* 2}}{2}-p_{i}{ }^{*} \\
& \frac{\sqrt{\boldsymbol{A}_{\text {ref }}}}{\boldsymbol{L}_{\text {ref }}} \sqrt{\frac{\boldsymbol{p}_{\text {ref }} \boldsymbol{A}_{\text {ref }}{ }^{2}}{\boldsymbol{\rho}_{\text {ref }} \boldsymbol{q}_{\text {ref }}{ }^{2}}} \sqrt{\frac{\rho_{\text {ref }} U_{\text {ref }}^{2}}{p_{\text {ref }}}} \frac{4 C_{z} A^{*}{ }^{3 / 2}}{\sqrt{\pi}} \frac{d q^{*}}{d t^{*}} \\
& =-q^{* 2} \operatorname{sign}\left(q^{*}\right)+\frac{\boldsymbol{p}_{\text {ref }} \boldsymbol{A}_{\text {ref }}{ }^{2}}{\boldsymbol{\rho}_{\text {ref }} \boldsymbol{q}_{\boldsymbol{r e f}}{ }^{2}} 2 C_{z}^{2} A^{* 2} \frac{\Delta p^{*}}{\rho^{*}} \\
& \left(\frac{\boldsymbol{V}_{\text {ref }} \boldsymbol{U}_{\text {ref }}}{\boldsymbol{L}_{\text {ref }} \boldsymbol{q}_{\text {ref }}}\right) V_{i}^{*} \frac{d \rho^{*}}{d t^{*}}=\sum \rho^{*} q^{*} \\
& \left(\frac{\boldsymbol{V}_{\boldsymbol{r e f}} \boldsymbol{U}_{\boldsymbol{r e f}}}{\boldsymbol{L}_{\boldsymbol{r e f}} \boldsymbol{q}_{\boldsymbol{r e f}}}\right) V_{i}^{*} c_{v} \frac{d p^{*}}{d t^{*}}=\sum \rho^{*} c_{p} q^{*} T^{*}
\end{aligned}
$$

Thus, we have identified 4 dimensionless numbers: equations (12) to (15).

$$
\begin{array}{ccc}
\Pi_{1}=\frac{\rho_{\text {ref }} U_{r e f}^{2}}{p_{\text {ref }}} & \text { (12) } & \Pi_{2}=\frac{p_{r e f} A_{r e f}^{2}}{\rho_{\text {ref }} q_{r e f}{ }^{2}} \\
\Pi_{3}=\frac{\sqrt{A_{r e f}}}{L_{\text {ref }}} & \text { (14) } \quad \Pi_{4}=\frac{V_{r e f} U_{r e f}}{L_{r e f} q_{r e f}}
\end{array}
$$




\subsection{Definition of the scales ratios}

To meet similarity conditions, the values of the dimensionless numbers $\Pi_{1}$ to $\Pi_{4}$ have to be identical at both model scale and real scale. For each variable, we define a scale ratio $\bar{X}=\frac{X_{\text {ref model }}}{X_{\text {ref real }}}$. We consider that the air has the same properties at model scale than at real scale: the scale ratio of air densities is equal to 1 . Thus, the conservation of $\Pi_{1}$ to $\Pi_{4}$ leads to the relation between scale ratios given in equations (16) to (19).

$$
\begin{array}{rlrl}
\bar{U} & =\bar{p} & (16) & \bar{p} \bar{A}^{2}=\bar{q}^{2} \\
\bar{A}^{0,5}=\bar{L} & \text { (18) } & \bar{V} \bar{U}=\bar{L} \bar{q}
\end{array}
$$

\subsection{Definition of the varying parameters of the experiment}

We design a model scale experiment for fan pressurization tests in order to study the impact of a steady wind for these tests. Thus, we need to define the physical parameters that we will need to vary for this study.

\subsubsection{Leakage distribution}

Carrie and Leprince [11] have shown that whereas the total leakage area is not a parameter of influence in the impact of the wind, the distribution between windward leak and leeward leak has a large impact on the error due to wind. Thus, we will design a model with different leak sizes to study different leakage distributions. We define a leakage distribution ratio $r_{L D}$ according to equation (20).

$$
r_{L D}=\frac{A_{1}}{A_{1}+A_{2}}
$$

As the leakage distribution in real buildings is extremely variable, we will study 9 configurations: from $r_{L D}=10 \%$ to $r_{L D}=90 \%$.

\subsubsection{Pressure difference sequence}

The requirements of the ISO 9972 [17] regarding the pressure difference are $10 \mathrm{~Pa}$ for the lowest and $50 \mathrm{~Pa}$ for the highest; a pressure difference up to $100 \mathrm{~Pa}$ is recommended. In order to reproduce pressurization test according to this standard, we define two ranges of pressure differences:

- $\quad[10 ; 70 \mathrm{~Pa}]$ is the range we have to be able to reach

- $[10 ; 100 \mathrm{~Pa}]$ is the range we might be able to reach.

\subsubsection{Wind velocity}

The ISO 9972, indicates that for a meteorological wind speed above $6 \mathrm{~m} \mathrm{~s}^{-1}$, the zero-flow pressure difference requirement is unlikely respected. In literature, the impact of the wind has been studied for wind speed up to $10 \mathrm{~m} \mathrm{~s}^{-}$ ${ }^{1}$ [11] and $12 \mathrm{~m} \mathrm{~s}^{-1}$ [13] and the limit of $6 \mathrm{~m} \mathrm{~s}^{-1}$ is often mentioned. In order to be able to confront our results to these studies, our objective is to vary the wind speed from 0 to more than $6 \mathrm{~m} \mathrm{~s}^{-1}$.

\section{Design of the experiment}

\subsection{Definition of real scale conditions}

We consider a generic 2 -storeys house whose geometrical characteristics are presented in Fig. 1. We consider this building to be representative of real single detached dwellings. The value of the $\mathrm{ELA}_{4}=0.014 \mathrm{~m}^{2}$ corresponds to the limit value required for new house in the current French EP-regulation $\mathrm{Q}_{4 \mathrm{P} a-\text { surf }}=0.6 \mathrm{~m}^{3} \mathrm{~h}^{-1} \mathrm{~m}^{-2}$ (leakage airflow rate at $4 \mathrm{~Pa}$ dividing by the envelope area excluding low basement )[18].

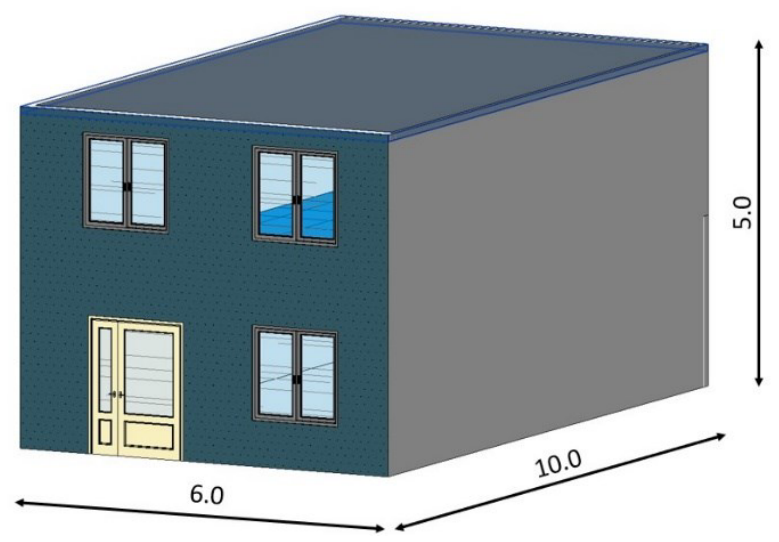

Fig. 1. Sizes of the generic 2-storey house at real scale [in $\mathrm{m}]$

\subsection{Design of the reduced model}

\subsubsection{Definition of the scale ratio}

The size of the model is constrained by the dimensions of the wind tunnel to be constructed. As the wind tunnel has to fit into the laboratory, the maximum cross section of its testing chamber has to be $1.0 * 1.0 \mathrm{~m}^{2}$. In order to avoid blockage analysis and correction, the cross section of the model has to be below $5 \%$ of testing chamber cross section, so $0.05 \mathrm{~m}^{2}$. This limit is defined by the ASCE as indicated by Choi and Kwon [19]. The cross section of the real house is $6 * 5=30 \mathrm{~m}^{2}$. Thus, we design our model from the real house sizes implementing a scale ratio of $1 / 25^{\text {th }}$. The geometrical characteristics of our model are presented in Fig. 2. The cross section of the model is $0.20 * 0.24=0.48 \mathrm{~m}^{2}$, which respect the $5 \%$ limit.

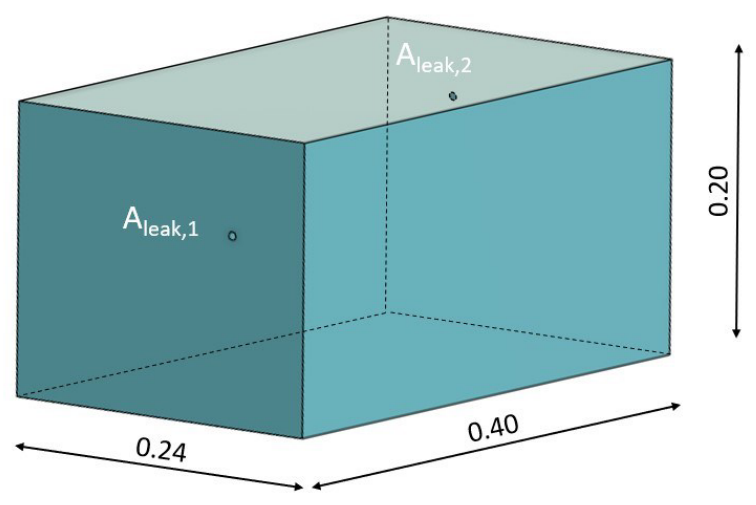

Fig. 2. Sizes of the reduced model [in $\mathrm{m}]$ 


\subsubsection{Definition of the openings size}

If we implement the $1 / 25^{\text {th }}$ scale ratio to leaks, we obtain small leaks with diameters less than $0.04 \mathrm{~mm}$. The airflow through one opening of this size will be completely laminar and we will not reproduce behavior of the airflow through real leaks. In order to reproduce the behavior of a real airflow, we decide to design only two openings in our model. This simplification is consistent with the numerical model we described in paragraph 2 . The total leakage area of the model remains consistent with the real house characteristics (equation (21))

$A_{1, \text { model }}+A_{2, \text { model }}=\frac{1}{25} E L A_{4, \text { real }}=2.310^{-5} \mathrm{~m}^{2}$

In order to study the wind impact with different leakage distributions, we define different diameters of the openings for a leakage distribution ratio $r_{L D}$ from $10 \%$ to $90 \%$.

\subsubsection{Technical solutions}

We design plastic facades fixed on a metallic frame with screws and seals. This solution offers the possibility to design in future experiments new facades with more openings for example. Each of the two facades with the openings integrates a large circular opening. We design several metallic cylinders, each of them is drilled to correspond to one leakage distribution ratio defined in paragraph 2.4.1. These cylinders can be plugged on the large circular opening like corks (Fig. 3). This solution let to design in future experiments as many different opening sizes and forms as possible.

In order to fix the model in the tunnel, the floor of the model is constituted by a large circular plane which includes:

- One block: it lets to place the model in a specific position

- Two clamps to fix the model on the wind tunnel and prevent it to move during one test.

In order to easily measure physical parameters inside the model, the floor of the model includes (Fig. 4):

- 2 taps on which we can connect flexible tubes to measure pressure differences or to supply air to pressurize the model;

- 17 circular openings to insert thermometer for example. For each opening, a sealing system is implemented to ensure the airtightness when the opening is not used.

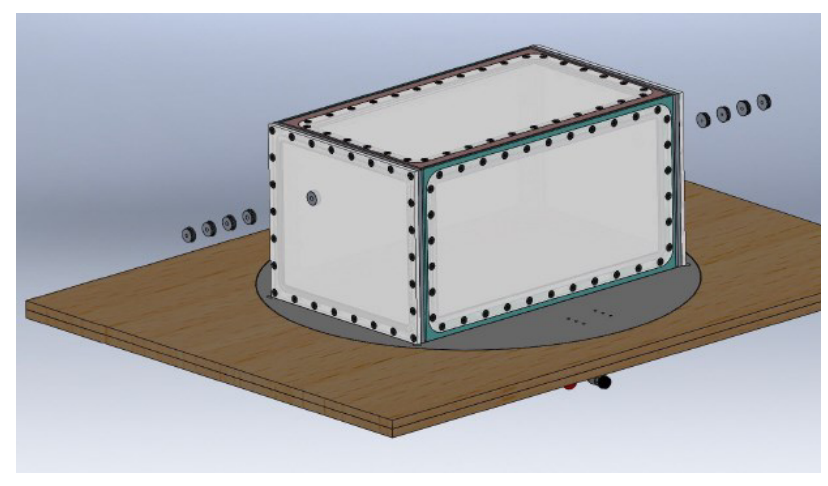

Fig. 3. Design drawing of the model - Details of the openings

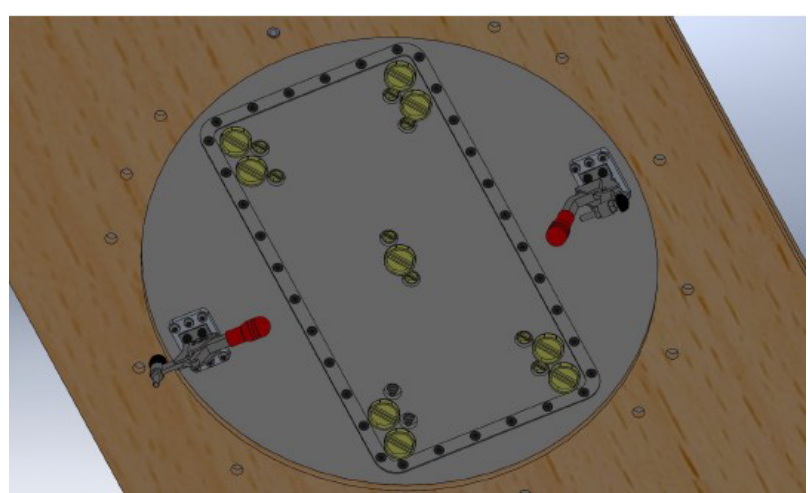

Fig. 4. Design drawing of the model - Details of the model floor

\subsection{Specifications for the pressurization device}

The pressurization device has to be able to:

- Impose pressure differences from 10 to $100 \mathrm{~Pa}$ for all configurations of leakage distributions and for wind speeds up to more than $6 \mathrm{~m} \mathrm{~s}^{-1}$

- Precisely measure the provided airflow.

We evaluate the airflow rate it will have to provide for the different wind conditions at each of the pressure differences of the test sequence, for all configurations of leakage distribution. In this study, we only consider a steady wind during a test. Then, for each leakage distribution configuration, each wind speed and each pressure difference imposed by the pressurization device, we calculate the theoretical airflow provided by the pressurization device using:

- equations (1) and (2) to determine the pressure differences at each opening;

- equations (3) and (4) to determine the airflow through each opening;

- equation (5) to determine the airflow rate provided by the pressurization device.

The range of this airflow is $\left[2.0 ; 20.01 \mathrm{~min}^{-1}\right]$. We identify a flow controller which meets these requirements: it provides airflow rate from $0.41 \mathrm{~min}^{-1}$ to $1001 \mathrm{~min}^{-1}$ and its uncertainty is $\pm 0.5 \%$ of the measured value \pm 0.096 $1 . \mathrm{min}^{-1}$.

\subsection{Design of the wind tunnel}

We design the wind tunnel in order to provide a steady wind from 0 to more than $6 \mathrm{~m} \cdot \mathrm{s}^{-1}$ in the test chamber. With this range of wind speed, our wind tunnel is a "Low speed wind tunnel" [20]. We apply the methodology explained by Mauro et al. [21] to design our wind tunnel. It includes:

1. A settling chamber with a honeycomb and 2 screens

2. A contraction

3. A testing chamber

4. A diffuser

5. A fan

\subsubsection{Testing chamber (TC) design}

As we explain in paragraph 3.2, the area of the cross section of the testing chamber is $1.0^{*} 1.0 \mathrm{~m}^{2}$ in order to fit into the laboratory. In order to easily install our model and different sensors, we fix the length of the TC at $1.5 \mathrm{~m}$. It 
respects the condition given by Stefano et al.: the length is between 0.5 and 3 times the hydraulic diameter of the TC $(1 \mathrm{~m})$. The floor of the TC includes a circular opening in which the model will be placed.

\subsubsection{Contraction design}

The contraction is the component that aims to 1) accelerate the flow in the TC and 2) profile a flow inside the TC with a uniform velocity profile. First, the ratio between the cross-section areas of the contraction should be in the range 4-6 [22] for a TC whose cross-section is bigger than $0.5 \mathrm{~m}$. For space considerations, we design a contraction with a ratio of 4: this leads to an upstream cross-section of $2.0 * 2.0 \mathrm{~m}^{2}$. Then, the form of the contraction is given by the Bell-Metha fifth order polynomials [23](Fig. 5). In order to reduce the difficulty of fabrication, we tested simplified forms with a CFD calculation. These CFD simulations compare wind behaviours with various angles of the contraction, from $25^{\circ}$ up to $45^{\circ}$ (Fig. 6). We choose the $30^{\circ}$ simplified contraction that offers an acceptable compromise between a small deviation in the velocity field in the flow direction (less than 3\% discrepancy from the Bell-Mehta form) and no difficulty of fabrication in our case.

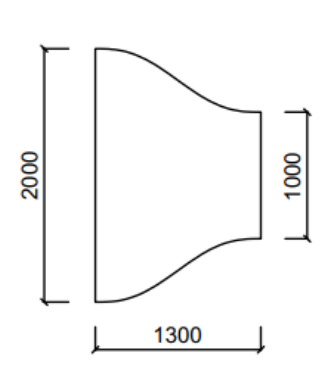

Fig. 5. Bell-Mehta contraction [in $\mathrm{mm}$ ]

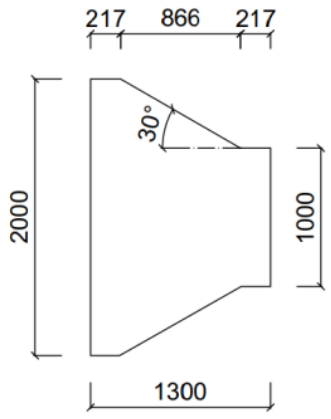

Fig. 6. Simplified contraction [in mm]

\subsubsection{Settling chamber design}

The cross section of the settling chamber is equal to the maximal cross section of the convection $2.0 * 2.0 \mathrm{~m}^{2}$. The settling chamber includes a honeycomb and two screens; each of these components is $2.0 * 2.0 \mathrm{~m}^{2}$.

According to Mauro et al., the honeycomb has to respect two conditions:

- $\quad$ Its porosity has to be above 0.8 ;

- The ratio between its length and the hydraulic diameter of its cells have to be between 6 and 8 .

We identify a honeycomb in aluminium with the following characteristics:

- $\quad$ Alveolus diameter $=6 \mathrm{~mm}$

- $\quad$ Sheet thickness $=0.7 \mathrm{~mm}$

- $\quad$ Length $=45 \mathrm{~mm}$

- $\quad$ Cross section $=2.0 * 2.0 \mathrm{~m}^{2}$

The porosity of the honeycomb is 0.8 and the ratio between length and hydraulic diameter is 7.5 , which is consistent with the conditions presented by Mauro et al. According to Prandtl [24], it is more efficient to have a series of screens with different porosities. Their porosity has to be between 0.58 and 0.8 . We identify two types of perforated plate: one in galvanized steel with a porosity of 0.64 and one in steel with a porosity of 0.74 .

\subsubsection{Diffuser and fan design}

In order to create a wind up to more than $6 \mathrm{~m} \mathrm{~s}^{-1}$ in the testing chamber, we need a fan providing an airflow rate up to around $40,000 \mathrm{~m}^{3} \mathrm{~h}^{-1}$. We need to control the speed of the fan in order to stabilize the wind inside the testing chamber at different velocities. We identify an axial fan with a maximum airflow rate which can reach around $43,000 \mathrm{~m}^{3} \mathrm{~h}^{-1}$, depending of the pressure drop. This fan can be controlled with a frequency converter. Its diameter is equal to $1.0 \mathrm{~m}$. As the diameter of the fan corresponds to the size of the testing chamber, we do not have a minimum length for the diffuser.

\subsubsection{Final design of the wind tunnel}

Fig. 7 shows the key components of our wind tunnel. Our wind tunnel is $4.11 \mathrm{~m}$ long with a maximal cross-sectional area of $4.0 \mathrm{~m}^{2}$.

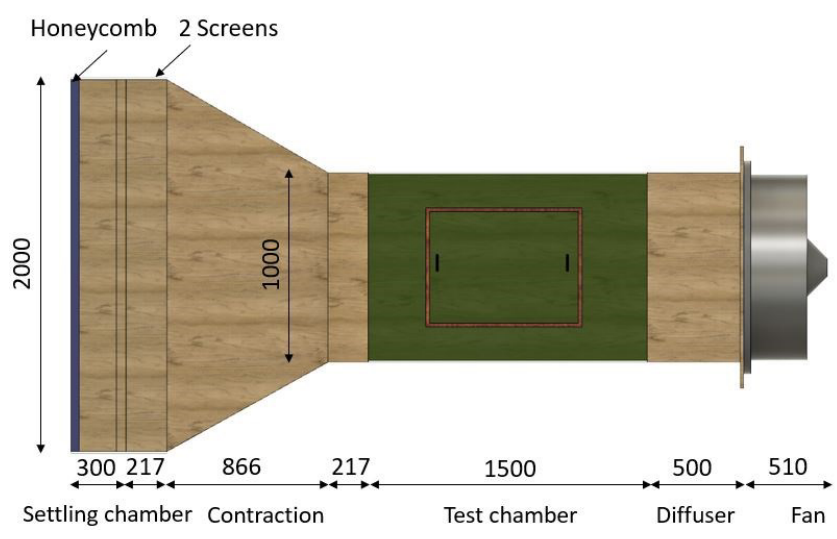

Fig. 7. Final dimension of wind tunnel [in $\mathrm{mm}]$

\section{Results}

\subsection{Model scale reproduction of a fan pressurization test}

We first test the airtightness of the model without voluntary leaks by submitting the model to a pressure difference $\Delta \mathrm{P}=200 \mathrm{~Pa}$, then we stop the pressurization and we analyse the evolution of the pressure inside the model. Fig. 8 compares the decrease of the pressure inside the model without voluntary leak to the decrease with the smallest one voluntary leak we have: a $1.7 \mathrm{~mm}$ diameter leak. With only the smallest leak, the pressure inside the building drops from $200 \mathrm{~Pa}$ to $0 \mathrm{~Pa}$ in less than 4 seconds. Without any voluntary leak, it takes more than 19 minutes to go from $200 \mathrm{~Pa}$ to $0 \mathrm{~Pa}$. This test shows that our model is extremely airtight. 


\section{Pressure decrease inside the model}

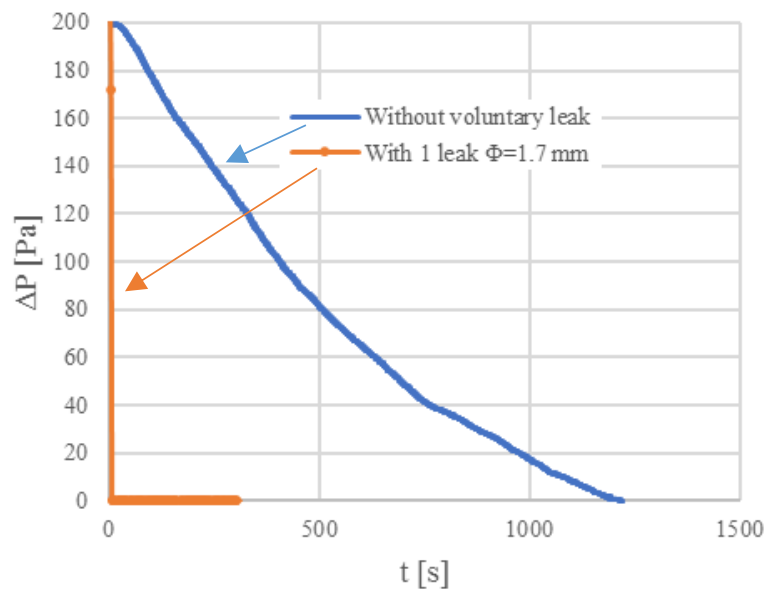

Fig. 8. Characterization of the airtightness of the model without voluntary leaks - Observation of the pressure decrease inside the model

Secondly, for each leakage distribution, we perform 5 pressurization tests under repeatability conditions with 10 steps from $10 \mathrm{~Pa}$ to $100 \mathrm{~Pa}$ without any wind in order to determine the exact airtightness of each configuration. Fig. 9 presents results of the five tests performed without wind under repeatability condition for the leakage distribution $r_{L D}=50 \%$. We notice no significant variation from one test to another: the airleakage coefficient $C_{L}$ is equal to $0.09 \mathrm{~m}^{3} \mathrm{~h}^{-1}$ and the flow exponent $\mathrm{n}$ is equal to 0.51 for the 5 tests. We observe the same repeatability for all airleakage distributions.

Fan pressurization tests results without wind for $\mathrm{r}_{\mathrm{LD}}=50 \%$

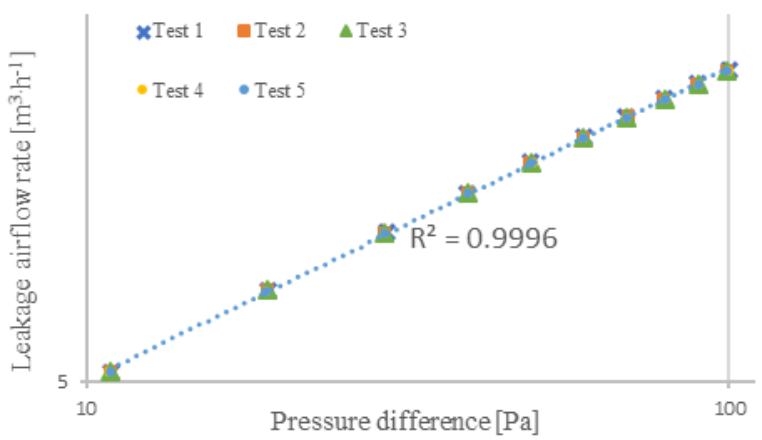

Fig. 9. Fan pressurization tests results without wind for the leakage distribution $\mathrm{r}_{\mathrm{LD}}=50 \%$

Table 1 presents the results of these tests including

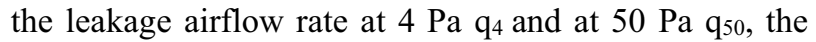
values for the airleakage coefficient $\mathrm{C}_{\mathrm{L}}$ and the flow exponent $\mathrm{n}$, and the values for the correlation coefficient $\mathrm{R}^{2}$ for all airleakage distributions. We notice no significant variation of the airtightness of the model from one configuration to another: the maximal variation is $0.02 \mathrm{~m}^{3} \mathrm{~h}^{-1}$ for the $\mathrm{q}_{50}$. The specific effective airleakage area at $4 \mathrm{~Pa} \mathrm{ELA}_{4}$ we obtain (mean measured $=2.06^{*} 10^{-5}$ $\mathrm{m}^{2}$ ) is smaller than the value we use to design the model $\left(2.3 * 10^{-5} \mathrm{~m}^{2}\right)$. This is due to the limit of precision during the manufacturing of the leaks. Our model is thus more airtight that the one we had designed. As we previously indicated, the airtightness does not significantly influence the impact of the wind during airleakage measurements. This difference between designed airtightness and real airtightness of our model will not have an impact on the future experiments.

Table 1. Airtightness of the model for each leakage distribution

\begin{tabular}{|c|c|c|c|c|c|c|}
\hline $\begin{array}{c}\text { Leakage } \\
\text { distribution } \\
\mathbf{r}_{\mathbf{L D}}\end{array}$ & $\begin{array}{c}\mathbf{q}_{\mathbf{4}} \\
{\left[\mathrm{m}^{3} \cdot \mathrm{h}^{-1}\right]}\end{array}$ & $\begin{array}{c}\mathbf{q}_{\mathbf{5 0}} \\
{\left[\mathrm{m}^{3} \cdot \mathrm{h}^{-1}\right]}\end{array}$ & $\begin{array}{c}\mathbf{E L A} \mathbf{4} \\
{\left[\mathrm{m}^{2}\right]}\end{array}$ & $\begin{array}{c}\mathbf{C}_{\mathbf{L}} \\
{\left[\mathrm{m}^{3} \cdot \mathrm{h}_{\mathrm{Pa}}\right]}\end{array}$ & $\mathbf{n}$ & $\mathbf{R}^{\mathbf{2}}$ \\
\hline $\mathbf{1 0 \%}$ & 0.19 & 0.68 & $2.08 \mathrm{E}-05$ & 0.10 & 0.50 & 0.9998 \\
\hline $\mathbf{2 0 \%}$ & 0.19 & 0.68 & $2.07 \mathrm{E}-05$ & 0.10 & 0.50 & 0.9997 \\
\hline $\mathbf{3 0 \%}$ & 0.19 & 0.69 & $2.06 \mathrm{E}-05$ & 0.09 & 0.51 & 0.9998 \\
\hline $\mathbf{4 0 \%}$ & 0.19 & 0.67 & $2.04 \mathrm{E}-05$ & 0.09 & 0.50 & 0.9997 \\
\hline $\mathbf{5 0 \%}$ & 0.19 & 0.69 & $2.04 \mathrm{E}-05$ & 0.09 & 0.51 & 0.9998 \\
\hline $\mathbf{6 0 \%}$ & 0.19 & 0.67 & $2.04 \mathrm{E}-05$ & 0.09 & 0.50 & 0.9997 \\
\hline $\mathbf{7 0 \%}$ & 0.19 & 0.69 & $2.05 \mathrm{E}-05$ & 0.09 & 0.51 & 0.9998 \\
\hline $\mathbf{8 0 \%}$ & 0.19 & 0.68 & $2.08 \mathrm{E}-05$ & 0.10 & 0.50 & 0.9998 \\
\hline $\mathbf{9 0 \%}$ & 0.19 & 0.68 & $2.09 \mathrm{E}-05$ & 0.10 & 0.50 & 0.9998 \\
\hline
\end{tabular}

Then in order to verify that it is possible to reach and stabilize pressure steps from $10 \mathrm{~Pa}$ to $100 \mathrm{~Pa}$ under windy conditions, we tested all leakage distribution. We perform fan pressurization tests for different wind speeds (from 0 $\mathrm{m} . \mathrm{s}^{-1}$ to the $7 \mathrm{~m} \mathrm{~s}^{-1}$ ). We observe that we are able to perform all the tests up to $100 \mathrm{~Pa}$ (Fig. 10 presents the pressure steps for $r_{L D}=20 \%$ with a mean wind speed $\left.\mathrm{U}_{\text {mean }}=4.3 \mathrm{~m} \cdot \mathrm{s}^{-1}\right)$. Thus, we are able to reproduce fan pressurization tests on our model for all the designed leakage distribution and for all wind speeds created in the wind tunnel.

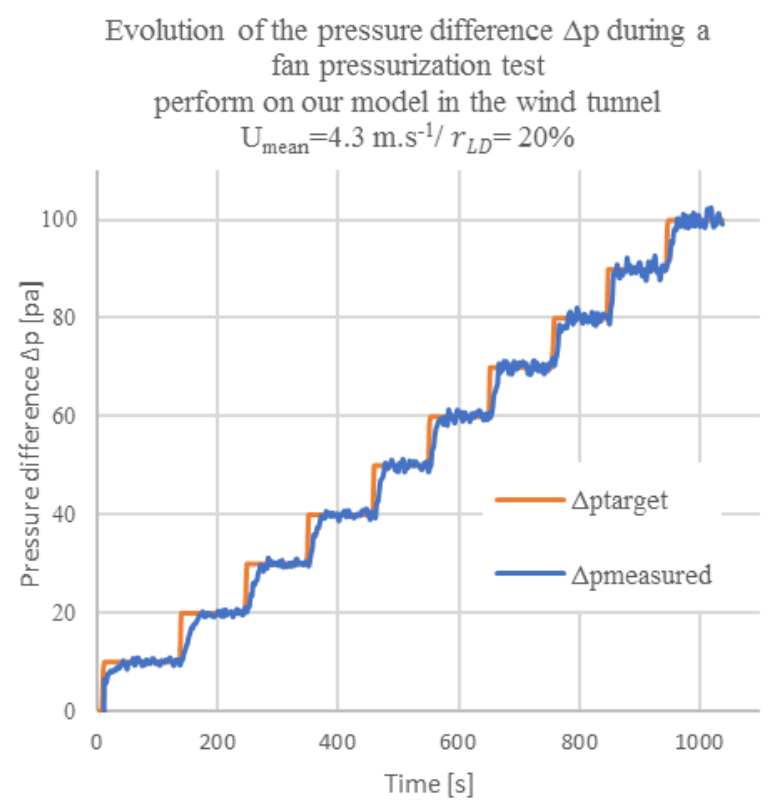

Fig. 10. Pressure steps for a fan pressurization test perform with a leakage distribution $\mathrm{r}_{\mathrm{LD}}=20 \%$ and a mean wind speed $\mathrm{U}_{\text {mean }}=4.3 \mathrm{~m} . \mathrm{s}^{-1}$ 


\subsection{Variation of experimental varying parameters for the wind impact study}

We test the homogeneity of the wind speed inside the testing chamber by measuring it at 42 equally spaced locations. We measure the wind speed at $25 \mathrm{~cm}$ from the ground of the testing chamber, for different wind speed configurations, during $1 \mathrm{~min}$ with 1 point per second. Fig. 11 gives the results of the measurements perform on 10 points for a wind speed around $4.6 \mathrm{~m} \mathrm{~s}^{-1}$. The maximum standard deviation of the 42 locations during a $1 \mathrm{~min}$ measurement is $0.087 \mathrm{~m} \mathrm{~s}^{-1}$ : this result confirms the temporal stability of the wind speed for each loca tion.

The minimal wind speed measured is $4.43 \mathrm{~m} \mathrm{~s}^{-1}$ and the maximal wind speed is $4.90 \mathrm{~m} \mathrm{~s}^{-1}$ : we observe a maximal distribution of wind speeds in the test chamber of $10 \%$.

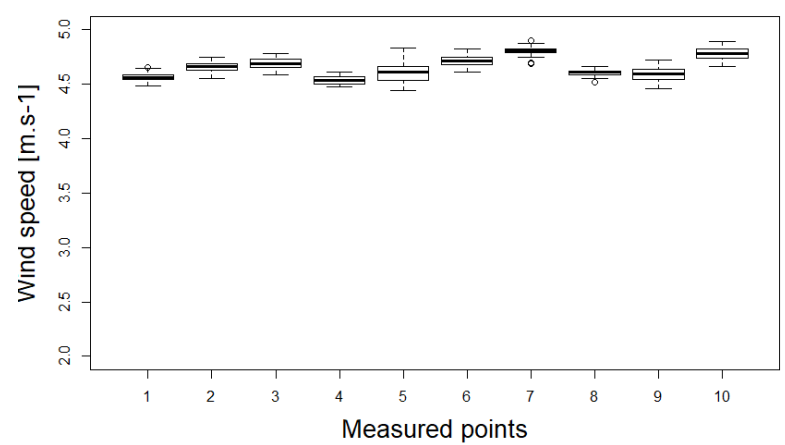

Fig. 11. Distribution of the wind speeds for 10 points in the testing chamber

\section{Conclusions}

In order to evaluate the impact of the wind during building airtightness measurements, we designed a model scale experiment based of the reproduction of fan pressurization tests. To respect similarity conditions, we defined sizes and characteristics for:

- The model that reproduces a single-zone building;

- The measuring device that replaces a blowerdoor;

- The wind tunnel that reproduces the wind.

First, we designed and built a complete low speed wind tunnel (length $=4.11 \mathrm{~m}$, maximal cross section $=4$ $\mathrm{m}^{2}$ ) in order to vary wind speed from $0 \mathrm{~m} \mathrm{~s}^{-1}$ to more than $6 \mathrm{~m} \mathrm{~s}^{-1}$. The wind speed inside the testing chamber presents good temporal and spatial stability: for a mean wind speed around $4.6 \mathrm{~m} \mathrm{~s}^{-1}$, the maximum standard variation at one point is $0.087 \mathrm{~m} \mathrm{~s}^{-1}$ and we observe a maximal distribution of wind speeds in the test chamber of $10 \%$.

Secondly, we designed and built a model representative of single family houses with a scale equal to $1 / 25^{\text {th }}$. This model includes two openings: one the windward wall and one on the leeward wall. The openings can be adjustable in 9 different leakage distributions that correspond to the same $\mathrm{q}_{4}=0.19 \mathrm{~m}^{3} \mathrm{~h}^{-1}$. The model without the voluntary leaks is extremely airtight: we know that the total leakage airflow goes through the two voluntary openings.
We gathered a flow controller and a manometer that reproduced a pressurization device. With these materials, we have been able to reproduce fan pressurization tests on the model for different wind speeds and different leakage distributions. For all those tests, we have been able to stabilize the pressure difference for steps up to $100 \mathrm{~Pa}$.

Thus, we are able to reproduce fan pressurization tests on our model in various wind situations and for different leakage distributions. Our experiment facility will now be used to evaluate the impact of the wind during airtightness measurements.

\section{References}

[1] G.T. Tamura, The relationship between tracer gas and pressurization techniques in dwellings, ASHRAE Trans. (1975) 202-211.

[2] F.R. Carrié, B. Rosenthal, An overview of national trends in envelope and ductwork airtightness, 2008.

[3] J. Jokisalo, J. Kurnitski, M. Korpi, T. Kalamees, J. Vinha, Building leakage, infiltration, and energy performance analyses for Finnish detached houses, Building and Environment. 44 (2009) 377-387. https://doi.org/10.1016/j.buildenv.2008.03.014.

[4] J.M. Logue, M.H. Sherman, I.S. Walker, B.C. Singer, Energy impacts of envelope tightening and mechanical ventilation for the U.S. residential sector, Energy and Buildings. 65 (2013) 281-291. https://doi.org/10.1016/j.enbuild.2013.06.008.

[5] V. Leprince, A. Bailly, F.R. Carrié, M. Olivier, State of the Art of Non-Residential Buildings Airtightness and Impact on the Energy Consumption, in: Proceedings of the 32nd AIVC Conference, 1213 October 2011, Brussels, Belgium, 2011: pp. 1213. http://www.aivc.org/sites/default/files/7b2.pdf.

[6] F. Richieri, B. Moujalled, T. Salem, F.R. Carrié, Airtightness impact on energy needs and airflow pattern: a numerical evaluation for mechanically ventilated dwellings in France, International Journal of Ventilation. 15 (2016) 134-150. https://doi.org/10.1080/14733315.2016.1203608.

[7] M.H. Sherman, W.R. Chan, Building Airtightness: Research and Practice. Building Ventilation: The State of the Art Review, LBNL Report. (2004).

[8] V. Leprince, F.R. Carrié, M. Kapsalaki, Building and ductwork airtightness requirements in Europe - Comparison of 10 European countries, in: Nottingham, UK, 2017.

[9] C. Mees, X. Loncour, Quality framework for reliable fan pressurisation tests, Qualicheck. (2016).

[10] M.P. Modera, D.J. Wilson, The Effects of Wind on Residential Building Leakage Measurements, Air Change Rate and Airtightness in Buildings. (1990). https://doi.org/10.1520/STP17210S.

[11] F.R. Carrié, V. Leprince, Uncertainties in building pressurisation tests due to steady wind, Energy and Buildings. $116 \quad$ (2016) 656-665. https://doi.org/10.1016/j.enbuild.2016.01.029.

[12] F.R. Carrié, V. Leprince, Model error due to steady wind in building pressurization tests, in: In 
Proceedings of 35th AIVC Conference, 24-25 September 2014, Poznan, Poland, 2014.

[13] I.S. Walker, M.H. Sherman, J. Joh, W.R. Chan, Applying Large Datasets to Developing a Better Understanding of Air Leakage Measurement in Homes, International Journal of Ventilation. 11 (2013).

https://www.tandfonline.com/doi/abs/10.1080/147 33315.2013.11683991 (accessed June 6, 2018).

[14] M. Prignon, A. Dawans, S. Altomonte, G. Van Moeseke, A method to quantify uncertainties in airtightness measurements: Zero-flow and envelope pressure, Energy and Buildings. 188-189 (2019)

$12-24$. https://doi.org/10.1016/j.enbuild.2019.02.006.

[15] F.R. Carrié, A.B. Mélois, Modelling building airtightness pressurisation tests with periodic wind and sharp-edged openings, Energy and Buildings. (2019). https://doi.org/10.1016/j.enbuild.2019.109642.

[16] N.L. Roux, Etude par similitude de l'influence du vent sur les transferts de masse dans les bâtiments complexes, 2011.

[17] ISO, EN ISO 9972: Thermal performance of buildings - Determination of air permeability of buildings - Fan pressurization method, (2015).

[18] F.R. Carrié, S. Charrier, Building regulations can foster quality management - the French example on building airtightness | QUALICHeCK, QUALICHeCK. (2015). http://qualicheckplatform.eu/2015/02/fact-sheet-01-buildingregulations-can-foster-quality-management/ (accessed January 12, 2020).

[19] C.-K. Choi, D.K. Kwon, Wind tunnel blockage effects on aerodynamic behavior of bluff body, Wind and Structures An International Journal. (1998).

[20] C. Ge, Design, construction and characterization of a wind tunnel, (n.d.) 60.

[21] S. Mauro, S. Brusca, R. Lanzafame, F. Famoso, A. Galvagno, M. Messina, Small-Scale Open-Circuit Wind Tunnel: Design Criteria, Construction and Calibration, International Journal of Applied Engineering Research. 12 (2017) 13649-13662.

[22] M.A. Gonzalez Hernandez, A.I. Moreno Lopez, A. A., J.M. Perales Perales, Y. Wu, S. Xiaoxiao, Design Methodology for a Quick and Low-Cost Wind Tunnel, in: N. Ahmed (Ed.), Wind Tunnel Designs and Their Diverse Engineering Applications, InTech, 2013. https://doi.org/10.5772/54169.

[23] J.H. Bell, R.D. Mehta, Contraction design for small low-speed wind tunnels, 1988. https://ntrs.nasa.gov/search.jsp?R=19890004382.

[24] L. Prandtl, Attaining a steady air stream in wind tunnels, (1933). http://ntrs.nasa.gov/search.jsp?R=19930094691 (accessed November 26, 2019). 